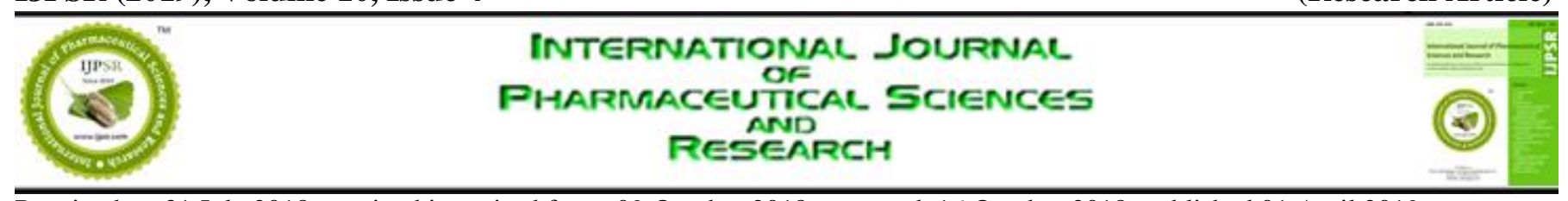

Received on 31 July 2018; received in revised form, 09 October 2018; accepted, 16 October 2018; published 01 April 2019

\title{
FORMULATION AND EVALUATION OF LORNOXICAM MOUTH DISSOLVING TABLET BY USING NATURAL SUPERDISINTEGRANTS
}

\author{
Nilesh V. Misal ${ }^{*}$ and Satyam Z. Chemate
}

Department of Pharmaceutics, Dr. V.V.P.F's College of Pharmacy (Savitribai Phule Pune University), Vilad Ghat, Ahmednagar - 414111, Maharashtra, India.

Keywords:

MDT, Gum karaya, Chitosan, Fenugreek seed mucilage, Lornoxicam

\section{Correspondence to Author:}

Nilesh V. Misal

Student,

Department of Pharmaceutics,

Dr. V.V.P.F's College of Pharmacy

(Savitribai Phule Pune University),

Vilad Ghat, Ahmednagar - 414111,

Maharashtra, India.

E-mail: nileshmisal171@gmail.com

\begin{abstract}
The concept of fast dissolving drug delivery system emerged from the desire to provide patients with more convenient means of taking their medication. It is difficult for many patients to swallow tablets and hard gelatin capsules. The main objective of the study is to develop a reproducible formulation of fast dissolving tablets of Lornoxicam already used the therapeutic molecule to enhance effectiveness and to avoid side effects (gastric irritation) of the drug. Different batches of tablets were prepared by direct compression method using a different concentration of superdisintegrants like gum karaya, chitosan, and fenugreek seed mucilage powder. Before compression pre-formulation studies were done which includes characterization of the blend and physical compatibility studies with excipients. Effect of change in super disintegrant and their concentration on the formulation was studied. Final batches were compared for the superiority of superdisintegrants in the formulation of MDT of Lornoxicam. Tablets were evaluated for weight variation, thickness, hardness, friability, drug content, in-vitro disintegrating time and in-vitro drug release.
\end{abstract} INTRODUCTION: The oral route of
administration continues to be the most preferred route due to its manifold advantages including ease of ingestion, pain avoidance, versatility, accurate dosage, self-medication and most importantly patient compliance. It has been shown that the dissolution rate of the pure drug can be altered significantly by the proper selection of formulation component as well as the processing method. Reports related to the effect of formulation excipients like diluents, disintegrants, surfactant, granulating agents and binders are available. In another set of works effect of processing factors such as method of granulation on the dissolution rate have been reported.

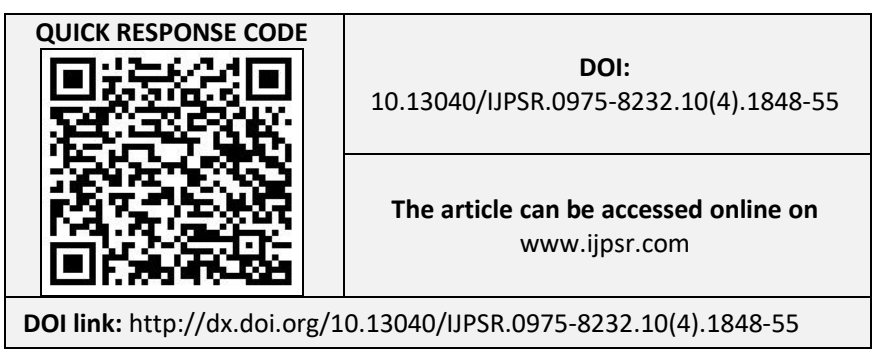

Ho and Hersey, have introduced a novel method of granulation based on the agglomeration due to prolonged grinding to improve the dissolution rate of paracetamol from tablets. The oral fastdissolving dosage forms, also known as fast-melt, fast disintegrating dosage forms, are a relatively novel dosage technology that involves rapid disintegration or dissolution of the dosage forms, into a solution or suspension in the mouth without the need for water. The dosage form begins to disintegrate immediately after coming into contact with saliva, with complete disintegration normally occurring within 30-50 sec after administration. The solution containing active ingredients is swallowed, and the active ingredients are then absorbed through the gastrointestinal epithelium to reach the target and produce the desired effect.

Fast dissolving tablets (FDT) are designed to improve patient acceptance and compliance. A survey of 6158 GP patients conducted in Norway indicated that approximately $26 \%$ of all patients do not take their prescribed medication as they 
encountered problems when swallowing conventional tablets. Often, the main complaints are the size, surface, and taste of the tablets. FDT help to overcome some of these problems: the rapid disintegration of the tablet into a solution containing the drug enables those who find difficulty in or experience discomfort when swallowing, to have a more patient-friendly experience. The target group for FDT is wideranging as people of all ages can experience difficulty in conventional tablets and capsules. This includes children and elderly who either experience difficulty and cannot swallow or have not learned to swallow the conventional solid dosage forms.

Also, institutionalized psychiatric patient as well as hospitalized or bedridden patients suffering from a variety of disorders such as stroke, thyroid disorder, Parkinson's disease, and other neurological disorders also find difficulty in swallowing and require fast melt tablets because of their physical condition. The convention and the ease of using FDTs are also essential to normal consumers, with some adults preferring this dosage forms as they are easy to handle and swallow, can be taken without water and have a rapid onset of action. For example, patients with limited access to water would also find such FDTs extremely beneficial.

Lornoxicam is a non-steroidal anti-inflammatory drug with extremely potent anti-inflammatory and analgesic activity. It is widely used for the symptomatic treatment of pain and inflammation in patients with rheumatoid arthritis and osteoarthritis. Moreover, it showed significant efficacy in various clinical trials in the management of perioperative and postoperative pain associated with gynecological, orthopedic, abdominal and dental surgeries. Lornoxicam exhibits distinct $\mathrm{pH}-$ dependent solubility characterized by very poor solubility in acidic condition present in the stomach.

Today, we have some plant-based pharmaceutical excipients, and various researchers have explored the utility of some of these plant-based materials as pharmaceutical super-disintegrants. Plant products serve as an alternative to synthetic products because of local accessibility, eco-friendly nature, bio-acceptable, renewable source, and lower prices compared to important synthetic products. Majority of investigations on natural polymers for disintegrant activity are centered on polysaccharides and proteins, due to their ability to produce a wide range of materials and properties based on their molecular structures.

Polysaccharide hydrocolloids including mucilages, gums, and glucans are abundant in nature and generally found in many higher plants. Mucilages are merely secondary plant metabolites, but due to the high concentration of hydroxyl groups in the polysaccharide, mucilages have typically a high water-binding capacity, and this has led to studies of their role in plant water relations. It has been suggested that the ability of mucilage to hydrate may offer a mechanism for plants to resist drought.

Therefore, natural gums and mucilages have been widely explored as disintegrants. Mucilages and gums are well known since ancient times for their medicinal use. In modern era they are widely used in pharmaceutical industries as thickeners, water retention agents, suspending agents and superdisintegrants. Mucilage is a glutinous substance which mainly consists of polysaccharides, proteins, and uranides. Dried up mucilage or the concentrated mucilage is called as gum. The main difference between them is that mucilage does not dissolve in water whereas gum dissolves in water ${ }^{1 \text {, }}$ 2,3

\section{MATERIALS AND METHODS:}

Materials: Lornoxicam was obtained gift sample from Abbott Healthcare Private Limited, Baddi, MCC (VIVAPUR 200) was purchased from JRS Pharma, gum karaya and fenugreek seed were purchase from Local Market Ahmednagar, chitosan was purchase from Ozone International, Mumbai, magnesium stearate, talc and saccharine from Loba Chemical, Mumbai, orange flavor was purchase from Himedia Lab, Nashik.

\section{Methods:}

Preparation of Lornoxicam MDT: Lornoxicam MDT prepare by direct compression method. Then powder blend punches into tablets weighing about $100 \mathrm{mg}$ containing $8 \mathrm{mg}$ of Lornoxicam (API), using rotary tablet compression machine. The different batches of Lornoxicam MDT were collected and stored in airtight container. 
TABLE 1: FORMULATION QUANTITIES IN mg/TABLET

\begin{tabular}{cccccccc}
\hline Composition & F0 & F1 & F2 & F3 & F4 & F5 & F6 \\
\hline Lornoxicam (mg) & 8 & 8 & 8 & 8 & 8 & 8 & 8 \\
Gum Karaya (mg) & - & 9 & 12 & - & - & - & - \\
Chitosan (mg) & - & - & - & 9 & 12 & - & - \\
Fenugreek (mg) & - & - & - & - & - & 9 & 12 \\
Avicel 101 (mg) & 81 & 72 & 69 & 72 & 69 & 72 & 69 \\
Saccharine (mg) & 4 & 4 & 4 & 4 & 4 & 4 & 4 \\
Talc (mg) & 3 & 3 & 3 & 3 & 3 & 3 & 3 \\
Magnesium sterate (mg) & 2 & 2 & 2 & 2 & 2 & 2 & 2 \\
Orange flavour (mg) & 2 & 2 & 2 & 2 & 2 & 2 & 2 \\
Average weight & $100 \mathrm{mg}$ & $100 \mathrm{mg}$ & $100 \mathrm{mg}$ & $100 \mathrm{mg}$ & $100 \mathrm{mg}$ & $100 \mathrm{mg}$ & $100 \mathrm{mg}$ \\
\hline
\end{tabular}

\section{Evaluation:}

Pre-compression Characteristics: The following parameters are determined.

Angle of Repose: The angle of repose of granules was determined by the funnel method. The accurately weighed granules were taken in a funnel. The height of the funnel was adjusted in such a way that the tip of the funnel just touched the apex of the heap of the granules. The granules were allowed to flow through the funnel freely onto the surface. The diameter of the powder cone was measured, and the angle of repose was calculated using the following equation: ${ }^{4,5}$

$$
\tan \theta=\mathrm{h} / \mathrm{r}
$$

Where $h$ and $r$ are the height and radius of the powder cone respectively.

Bulk Density: Both loose bulk density (LBD) and tapped bulk density (TBD) were determined. A quantity of $2 \mathrm{~g}$ of powder from each formula, previously lightly shaken to break any agglomerates formed, was introduced into a $10 \mathrm{ml}$ measuring cylinder. After the initial volume was observed, the cylinder was allowed to fall under its weight onto a hard surface from the height of 2.5 $\mathrm{cm}$ at 2 -sec intervals. The tapping was continued until no further change in volume was noted. LBD and TBD were calculated using the following formulas: ${ }^{4,5}$

$$
\text { LBD }=\text { Weight of the powder / Volume of packing }
$$

$\mathrm{TBD}=$ Weight of the powder $/$ Tapped volume of packing

Compressibility Index: The compressibility index of the granules was determined by Carr's compressibility index ${ }^{4,5}$.

$$
\text { Carr's index }(\%)=(\mathrm{TBD}-\mathrm{LBD}) \times 100 / \mathrm{TBD}
$$

Hausner's Ratio: The Hausner's ratio is a number that is correlated to the flowability of a powder or granular material $^{4,5}$.

$$
\text { Hausner's ratio }=\mathrm{TD} / \mathrm{BD}
$$

\section{Post-compression Evaluation:}

General Appearance: General appearance is the physical appearance of the tablet; it has two aspects to address.

First one is the patient compliance if the table is appearance is legible and good, it improves patient compliance. The second one is for the manufacturer; it helps him in trouble-free manufacturing if there is the tablet to tablet, batch to batch and lot to lot uniformity of tablet. A general appearance would include some aspects like size, shape, odor, taste, texture, legibility and identifying marks ${ }^{6}$.

Size and Shape: Different shapes and size of the tablet are available in the market they are manufactured in order. Too different, they based on their purpose of use and quantity of active ingredient. The age group of the patient who is going to be administrated with the drug. The shape and size of a tablet would vary based on tooling used in tablet manufacturing. The crown size is measured by using a micrometer and sliding Calliper scale is used to measure the size of 5 to 10 at a time. In laboratory scale tablet size measured by the Vanier Calliper. Tablet thickness should be controlled within $\pm 5 \%$ variation of a standard value ${ }^{6}$.

Hardness: Tablet hardness and strength are essential to see that the tablet can with the shock and stress during manufacturing packaging and transportation, and while handled by the patient. For each formulation, the hardness of tablet determined using the Monsanto hardness tester. 
The tablet was held along its oblong axis in between the two jaws of the tester. At this point, reading should be zero $\mathrm{kg} / \mathrm{cm}^{2}$. Then constant force was applied by rotating the knob until the tablet fractured. The value at this point was noted in $\mathrm{kg} .{ }^{6}$

Organoleptic Characters of Tablet: In which taste, odor, color, the shape of the tablet is noted. It is the preliminary test for IPQC of tablet ${ }^{6}$.

Friability: Twenty tablets were rotated in a friabilator (Roche) at $25 \mathrm{rpm}$ for $4 \mathrm{~min}$. The tablets were then dedusted, and the loss in weight due to fracture or abrasion was recorded as percentage weight loss ( $\%$ friability) ${ }^{6}$.

$$
\text { Friability }(\%)=\frac{\text { Initial Weight }- \text { Final Weight }}{\text { Initial Weight }} \times 100
$$

Weight Variation Test: Weight variation test is performed to check that the manufactured tablets have a uniform weight. As per USP, twenty tablets are weighed individually, and compendia weight is taken, the average weight is obtained by dividing compendia weight by 20 tablet weight, now the average weight is compared with the individual weight of the tablet. For a tablet to pass the test not more than 2 tablets should lie out of the specified percentage and if no tablet differs by more than two times the percentage limit ${ }^{6}$.

Drug Content: Three tablets were weighed individually, then crushed in a mortar. The drug weight equivalent to $10 \mathrm{mg}$ was taken, and dilution was prepared to form concentration up to range 10 ppm concentration. Finally, the absorbance of the prepared solution was checked and compared with theoretical value ${ }^{6}$.

\section{In-vitro Disintegration Time: In-vitro} disintegration time was performed by apparatus specified in USP at $50 \mathrm{rpm}$. Phosphate buffer $\mathrm{pH}-$ 6.8, $900 \mathrm{ml}$ was used as disintegration medium, and the temperature of which maintained at $37 \pm 0.2{ }^{\circ} \mathrm{C}$ and the time in sec taken for complete disintegration of the tablet with no palpable mass remaining in the apparatus was measured in seconds ${ }^{6}$.

In-vitro Drug Release Study: The in-vitro dissolution study of formulated Lornoxicam mouth dissolving tablets were carried out using USP apparatus Type-II in $900 \mathrm{ml}$ of phosphate buffer solution (pH 6.8) at $37{ }^{\circ} \mathrm{C} \pm 0.5{ }^{\circ} \mathrm{C}$ at a rotational speed $50 \mathrm{rpm}$. After each $5 \mathrm{~min}$ starting the test, 5 $\mathrm{ml}$ sample of dissolution medium was withdrawn and analyzed spectrophotometrically at $376 \mathrm{~nm}$ by using Shimadzu-1700 UV / visible spectrophotometer. An equal volume of fresh dissolution medium, maintained at the same temperature, was added after withdrawing each sample to maintain the volume. The absorbance values were transformed to concentration by reference to a standard calibration curve obtained experimentally 6

\section{Drug - Excipients Compatibility Studies:}

Differential Scanning Calorimetry (DSC) Studies: DSC study was carried out to check the compatibility of ingredients. DSC of Lornoxicam was taken for identification. Finally, a physical mixture of all the above ingredients was scanned for $\operatorname{DSC}^{7}$.

By Infrared Spectroscopy: The infrared spectra of pure Lornoxicam was recorded by Shimadzu IR Affinity (class 1 lesser product) spectrometer. The directly place on the lesser point and examined in the transmission mode. Spectrum was measured over a frequency range of $5000-500 \mathrm{~cm}^{-1}$. The peaks obtained in the spectra were then compared with corresponding functional groups in the structures of Lornoxicam ${ }^{7}$.

UV Spectroscopy Analysis: The absorbance maxima has been specified is determined by using UV. From the U.V analysis, it was concluded that the compound had shown $\lambda_{\max }$ at $376 \mathrm{~nm}$. Therefore, the observed $\lambda_{\max }$ of Lornoxicam 376 $\mathrm{nm}$ has selected for further experimental work in pH 6.8 Phosphate buffer ${ }^{7,8}$.

\section{RESULTS AND DISCUSSION:}

Beer's Lamberts Plot of Lornoxicam in pH Buffer: The concentrations and absorbance of Lornoxicam were given in Table 2.

\begin{tabular}{|c|c|c|}
\hline $\begin{array}{l}\text { S. } \\
\text { no. }\end{array}$ & Parameters & $\begin{array}{c}\text { Value in pH } 6.8 \text { phosphate } \\
\text { buffer solution }\end{array}$ \\
\hline 1 & $\begin{array}{c}\text { Absorbance maximum } \\
\left(\lambda_{\max }\right) \text { in } \mathrm{nm}\end{array}$ & $376 \mathrm{~nm}$ \\
\hline 2 & Slope & 0.0459 \\
\hline 3 & Intercept & 0.0031 \\
\hline 4 & Correlation Coefficient & 0.999 \\
\hline 5 & Equation & $Y=0.0459 x+0.0031$ \\
\hline
\end{tabular}


The concentration $v s$. absorbance plot was shown in Fig. 2. The solutions obeyed Beer-Lambert's Law over a concentration range of 2 to $10 \mu \mathrm{g} / \mathrm{mL}$ with a regression coefficient. $\mathrm{R}^{2}$ of at least 0.999 was achieved. The regression equation of Lornoxicam was $y=0.0459 x+0.0031$. This was utilized in the determination of in-vitro drug release of different Lornoxicam formulations.

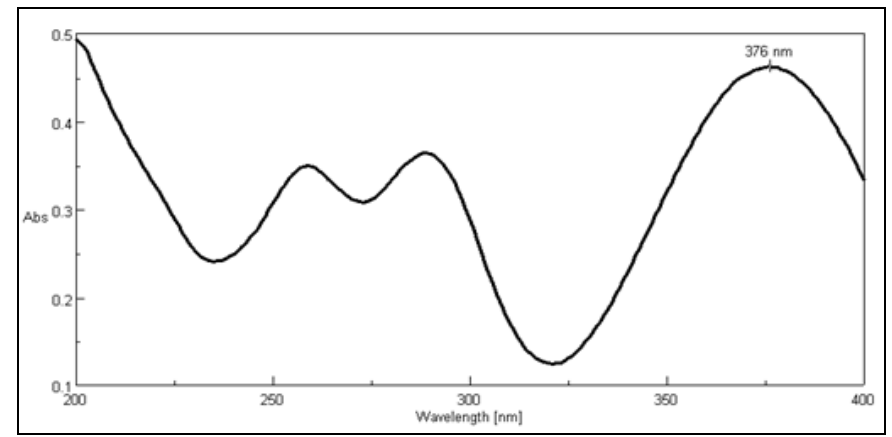

FIG. 1: UV SPECTRA OF LORNOXICAM

Differential Scanning Calorimetry (DSC) Studies: The thermal behavior of the pure drug (Lornoxicam) and optimized formulation was characterized by using DSC and graph was shown in Fig. 3 and 4. The DSC thermogram of Lornoxicam showed an exothermic peak at

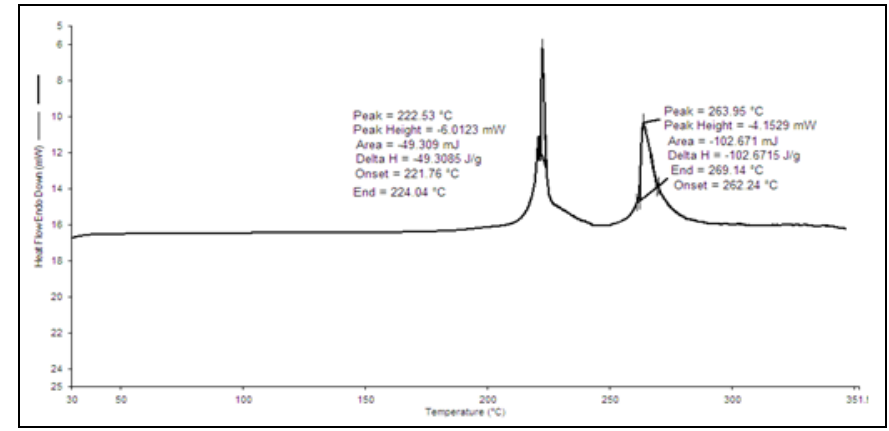

FIG. 3: DSC OF LORNOXICAM

Infrared Spectroscopy Study: The Infra-Red absorption spectrum of the finely ground sample in $\mathrm{KBr}$ dispersion compressed into a disc should
TABLE 3: ABSORBANCE OF LORNOXICAM

\begin{tabular}{ccc}
\hline S. no. & Conc. $(\mathbf{m g} / \mathbf{m L})$ & Absorbance $(\mathbf{n m})$ \\
\hline 1 & 0 & 0.0 \\
2 & 2 & 0.0924 \\
3 & 4 & 0.1791 \\
4 & 6 & 0.2805 \\
5 & 8 & 0.3686 \\
6 & 10 & 0.4652 \\
\hline
\end{tabular}

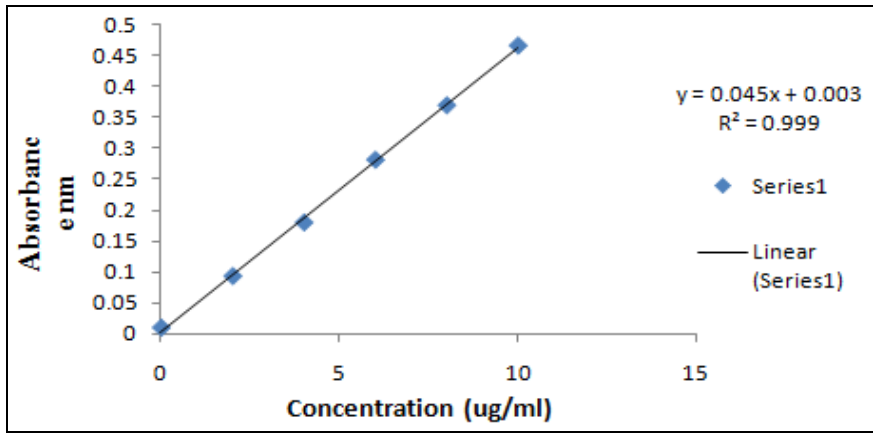

FIG. 2: CALIBRATION CURVE

$222.53^{\circ} \mathrm{C}$. The DSC thermogram of optimized formulation showed an exothermic peak at $216.01^{\circ} \mathrm{C}$. It indicates that there was no interaction found between drug and other excipients used in MDT of Lornoxicam formulation.

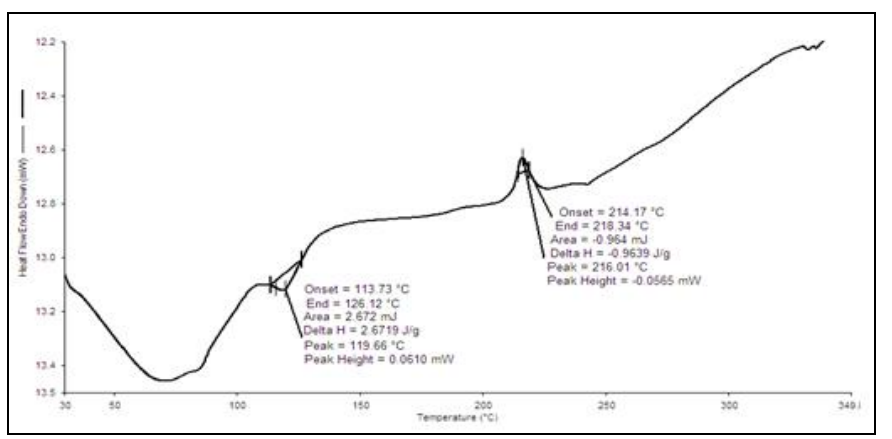

FIG. 4: DSC OF LORNOXICAM TABLET FORMULATION 12 mg GUM KARAYA

exhibit maxima only at the same wavelengths as that of a similar preparation of working standard.

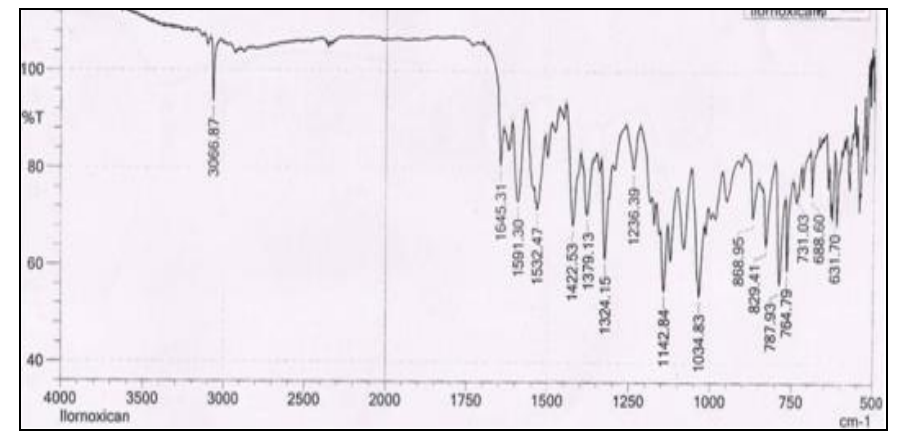

FIG. 5: IR SPECTRA OF LORNOXICAM

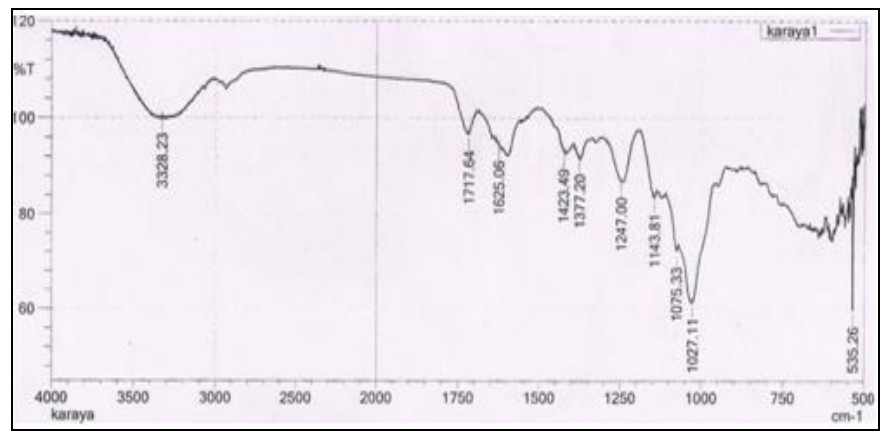

FIG. 6: IR SPECTRA OF GUM KARAYA 


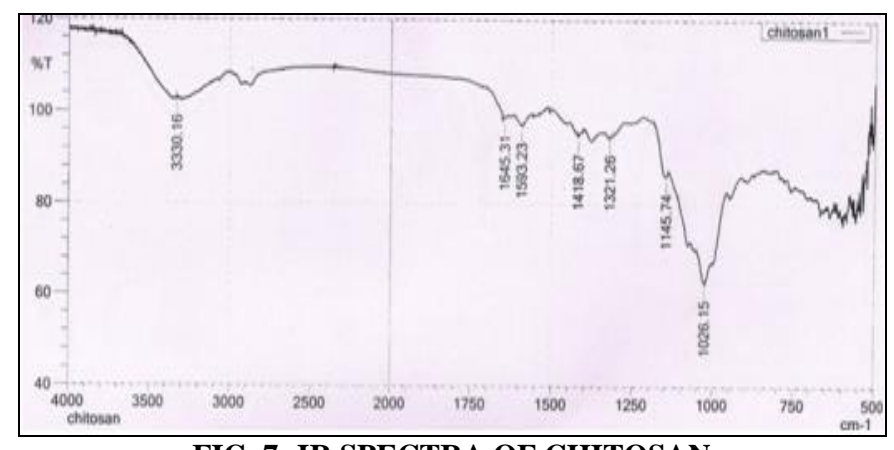

FIG. 7: IR SPECTRA OF CHITOSAN

IR Spectrum: The infrared spectrum of Lornoxicam confirms the presence of the relevant functional groups (as the important peaks are listed in Table and are compared with the literature. FTIR spectrum of Lornoxicam displays a characteristic $-\mathrm{NH}_{2}$ absorption peak at $1621 \mathrm{~cm}^{-1}$, which is a normal range of absorption of primary amines. It exhibits a strong band for $\mathrm{C}=\mathrm{O}$ stretching of the nonconjugated carboxylic acid at $1645 \mathrm{~cm}^{-1}$ whereas the second band which is expected to shift to a lower frequency (owing to conjugation) appears as an overlapping band. The $\mathrm{O}=\mathrm{S}=\mathrm{O}$, as well as acyclic amide, appears at 1379 $\mathrm{cm}^{-1}$. The corresponding C-H stretching appears in the region $1532-1501 \mathrm{~cm}^{-1}$.

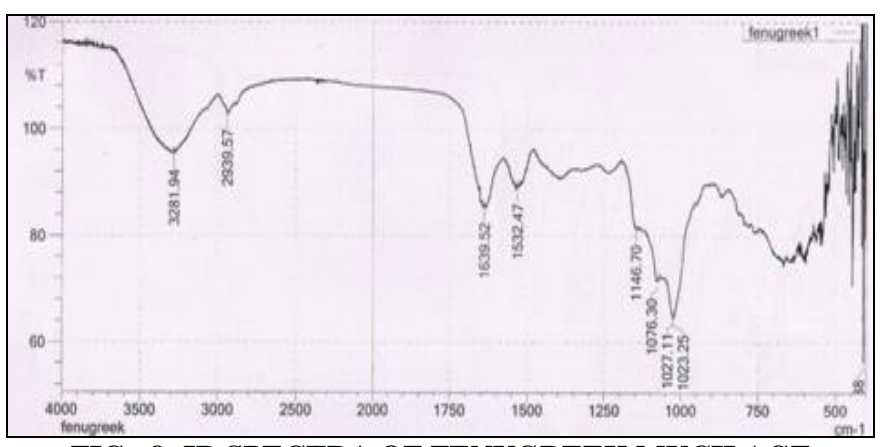

FIG. 8: IR SPECTRA OF FENUGREEK MUCILAGE

Evaluation of Powder: The prepared mouth dissolving tablet by direct compression method are initially evaluated for pre-compression variables like bulk density, tapped density, Hausner's ratio, \% compressibility, the angle of repose and the values are shown in Tables 4.

Bulk density values are in between 0.395-0.471, tapped density values are in between $0.444-0.569$, $\%$ compressibility values are in between 13.1715.11 , the angle of repose values are in between $19^{\circ} 42-20^{\circ} 18$. From these reported values, it was observed that all the powder blends show good flow properties. So these are suitable to prepare mouth dissolving tablet by direct compression.

TABLE 4: PRE COMPRESSION PARAMETER

\begin{tabular}{cccccc}
\hline Formulation & $\begin{array}{c}\text { Bulk density } \\
(\mathbf{g} / \mathbf{c c})\end{array}$ & $\begin{array}{c}\text { Tapped density } \\
(\mathbf{g} / \mathbf{c c})\end{array}$ & $\begin{array}{c}\text { \% } \\
\text { Compressibility }\end{array}$ & $\begin{array}{c}\text { Hausners } \\
\text { ratio }\end{array}$ & $\begin{array}{c}\text { Angle of repose } \\
(\text { Degree })\end{array}$ \\
\hline F0 & $0.463( \pm 0.24)$ & $0.543( \pm 0.58)$ & $14.81( \pm 0.023)$ & $1.18( \pm 0.10)$ & 19.42 \\
F1 & $0.414( \pm 0.34)$ & $0.479( \pm 0.75)$ & $14.26( \pm 0.014)$ & $1.16( \pm 0.08)$ & 20.18 \\
F2 & $0.395( \pm .028)$ & $0.444( \pm 0.46)$ & $13.17( \pm 0.20)$ & $1.15( \pm 0.07)$ & 19.95 \\
F3 & $0.463( \pm .018)$ & $0.543( \pm 0.54)$ & $14.81( \pm 0.06)$ & $1.18( \pm 0.10)$ & 20.08 \\
F4 & $0.471( \pm .039)$ & $0.569( \pm 0.49)$ & $14.30( \pm 0.17)$ & $1.18( \pm 0.10)$ & 19.88 \\
F5 & $0.468( \pm 0.29)$ & $0.545( \pm 0.62)$ & $14.88( \pm 0.14)$ & $1.17( \pm 0.09)$ & 19.76 \\
F6 & $0.466( \pm 0.42)$ & $0.549( \pm 0.64)$ & $15.11( \pm 0.18)$ & $1.17( \pm 0.09)$ & 19.82 \\
\hline
\end{tabular}

Evaluation of Tablet:

Organoleptic Characters of Tablet:

TABLE 5: ORGANOLEPTIC PROPERTY

\begin{tabular}{clll}
\hline Formulation & Colour & Odor & Shape \\
\hline F0 & Yellow & Fruity & Round \\
F1 & Yellow & Fruity & Round \\
F2 & Yellow & Fruity & Round \\
F3 & Yellow & Fruity & Round \\
F4 & Yellow & Fruity & Round \\
F5 & Yellow & Fruity & Round \\
F6 & Yellow & Fruity & Round \\
\hline
\end{tabular}

TABLE 6: EVALUATION PARAMETER

\begin{tabular}{ccccccc}
\hline Formulation & $\begin{array}{c}\text { Weight } \\
\text { variation }\end{array}$ & Thickness & Hardness & Friability & $\begin{array}{c}\text { Disintegration } \\
\text { Time }\end{array}$ & $\begin{array}{c}\text { \% Drug } \\
\text { content }\end{array}$ \\
\hline F0 & 101.07 & 5.1 & 3.50 & 0.1088 & 372 & 93.60 \\
F1 & 100.85 & 5.0 & 3.70 & 0.1267 & 190 & 99.94 \\
\hline
\end{tabular}




\begin{tabular}{lllllll}
\hline F2 & 101.87 & 5.2 & 3.75 & 0.1188 & 102 & 97.60 \\
F3 & 100.22 & 5.0 & 3.50 & 0.1012 & 252 & 90.97 \\
F4 & 101.60 & 4.9 & 3.40 & 0.1147 & 218 & 98.72 \\
F5 & 101.10 & 5.2 & 3.60 & 0.1207 & 307 & 91.98 \\
F6 & 100.30 & 5.0 & 3.40 & 0.1023 & 280 & 99.40 \\
\hline
\end{tabular}

Dissolution Studies (\% Drug Release):

TABLE 7: DISSOLUTION STUDY

\begin{tabular}{cccccccc}
\hline Time (min) & F0 & F1 & F2 & F3 & F4 & F5 & F6 \\
\hline 0 & 00 & 00 & 00 & 00 & 00 & 00 & 00 \\
5 & 17.89 & 30.66 & 32.24 & 31.59 & 31.59 & 29.86 & 32.04 \\
10 & 26.24 & 37.62 & 44.04 & 41.58 & 39.11 & 43.39 & 39.41 \\
15 & 47.39 & 45.89 & 50.09 & 48.11 & 45.90 & 47.34 & 48.52 \\
20 & 58.59 & 61.47 & 67.62 & 59.86 & 61.33 & 59.08 & 59.94 \\
25 & 68.69 & 74.59 & 81.97 & 68.23 & 79.06 & 76.49 & 78.27 \\
30 & 76.39 & 95.14 & 96.24 & 92.60 & 94.76 & 94.98 & 93.69 \\
\hline
\end{tabular}

Drug Dissolution Profile with Release Pattern: The drug release of formulations prepared with superdisintegrants by the direct compression method was performed by dissolution apparatus, the results were shown in Table 7 and graph was shown in Fig. 9. From the results, it was found that as the $12 \mathrm{mg}$ gum karaya formulation F2 showed maximum release. The formulation F2 shows 96.24 $\%$ drug release in 30 min. The $\mathrm{F} 2$ is the optimized formulation of all these series of formulations.

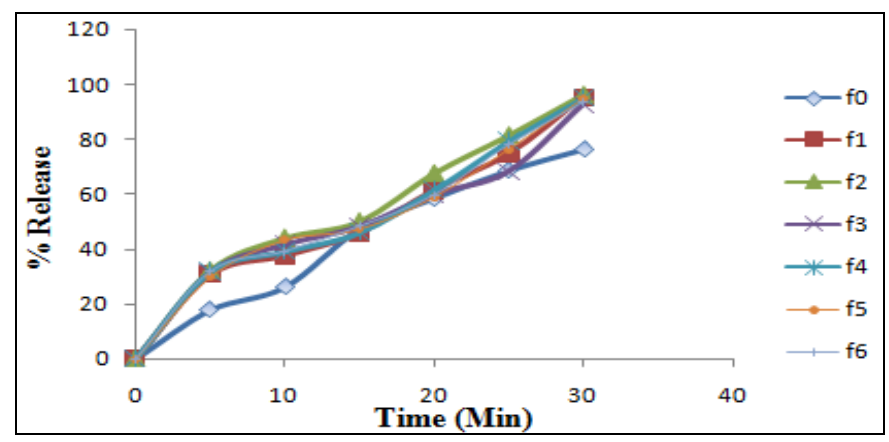

FIG. 9: DRUG RELEASE PROFILE OF LORNOXICAM MDT

CONCLUSION: Lornoxicam is poorly soluble in water. The natural materials like gums and mucilages have been extensively used in the field of drug delivery for their easy availability, costeffectiveness, eco-friendliness, emollient and nonirritant nature, nontoxicity, capable of a multitude of chemical modifications, potentially degradable and compatible due to natural origin. The evaluation studies showed that natural and synthetic super disintegrants differed in their ability to disintegrate the Lornoxicam. Oro-dispersible tablets when used in different concentrations. Hence, such a difference can potentially affect the drug dissolution rate. The Orodispersible tablets developed in this study will hopefully contribute to improving the drug administration to the patients with difficult to access water (travelers and mentally ill) and also suffering swallowing problems. These tablets much useful for treating acute pain conditions.

It can be concluded from the whole study that fast dissolving tablets of Lornoxicam drug, natural superdisintegrants can be used as pharmaceutical excipients for oral drug delivery. It was found that the formulation F2 maximum percentage drug release was found $96.24 \%$ with gum karaya $12 \mathrm{mg}$. Therefore, it was concluded that natural superdisintegrate like gum karaya showed the better disintegrating property.

ACKNOWLEDGEMENT: I thankful to Principal Dr. P. Y. Pawar and Dr. S. Z. Chemate, HOD Pharmaceutics, Dr. V.V.P.F's College of Pharmacy, Vilad Ghat, Ahmednagar for providing infrastructure and facilities to carry out this study.

\section{CONFLICT OF INTEREST: Nil}

\section{REFERENCES:}

1. Nareda M, Sharma AK, Nareda S, Ghadge M, Garg S and Sharma P: Design and formulation of fast dissolving tablet of Lornoxicam using banana powder as natural super disintegrant by direct compression Method. WJPPS 2018; 7(2): 631-642.

2. Ravikumar: Isolation and evaluation of disintegrant properties of fenugreek seed mucilage. International Journal of Pharmtech Research 2009; 982-996.

3. Mor J, Chauhan P and Jalwal P: Development and evaluation of oral fast dissolving tablets of Lornoxicam using superdisintegrants - A comparative study. The Pharma Innovation Journal 2016; 5(7): 01-07. 
4. Sahitya G, Krishnamoorthy B and Muthukumaran M: Importance of pre-formulation studies in designing formulations for sustained release dosage forms. International Journal of Pharmacy and Technology 2012; 4(4): 2311-2331

5. Lachman L and Lieberman HA: The theory and practice of industrial pharmacy, tablets. Varghese Publishing House Bombay, Edition $4^{\text {th }}, 2013$.

6. Haritha B: A Review on evaluation of tablets. Journal of Formulation Science and Bioavailability 2017; 1(1): 1-5.

7. Chatwal RG and Anand KS: Instrumental method of chemical analysis. Infrared Absorption Spectroscopy, Himalaya Publishing House 2011.
8. Thireesha B and Prasad AR: Development and validation of a simple UV spectrophotometric method for the determination of Lornoxicam in $0.75 \%$ w/v Pva solution. Indo American Journal of Pharmaceutical Research 2016: 6470-6477.

9. Nareda M, Sharma AK, Nareda S, Ghadge M, Garg S and Sharma P: Design and formulation of fast dissolving tablet of Lornoxicam using banana powder as natural super disintegrant by direct compression Method. WJPPS 2018; 7(2): 631-642.

10. Godara: Lornoxicam: A review of its therapeutic potential in different clinical studies. Journal of Drug Delivery \& Therapeutics 2013; 3(2): 145-148.

How to cite this article:

Misal NV and Chemate SZ: Formulation and evaluation of Lornoxicam mouth dissolving tablet by using natural superdisintegrants. Int J Pharm Sci \& Res 2019; 10(4): 1848-55. doi: 10.13040/IJPSR.0975-8232.10(4).1848-55.

All @ 2013 are reserved by International Journal of Pharmaceutical Sciences and Research. This Journal licensed under a Creative Commons Attribution-NonCommercial-ShareAlike 3.0 Unported License.

This article can be downloaded to Android OS based mobile. Scan QR Code using Code/Bar Scanner from your mobile. (Scanners are available on Google Play store) 